Journal of Research in Interprofessional

Practice and

Education

Vol. 2.2

February, 2012

\title{
The RIPPER Experience: A Three-Year Evaluation of an Australian Interprofessional Rural Health Education Pilot
}

\author{
Jessica Woodroffe, BA, PhD; Judy Spencer, MEd, BHSc, RN RPN; \\ Kim Rooney, MD, M.B.B.S F.R.A.C.P, FFAChPm, MA; \\ Quynh Le, PhD, M.Ed., B.Eng.; \& Penny Allen, PhD, MPH, BA
}

\begin{abstract}
Background: The Rural Interprofessional Program Educational Retreat (RIPPER) uses interprofessional learning and educational strategies to prepare final year Tasmanian nursing, medical, and pharmacy students for effective healthcare delivery. RIPPER provided students $(n=90)$ with the opportunity to learn about working in an interdisciplinary team using authentic and relevant situational learning. RIPPER allowed students to work and learn interprofessionally in small teams and to apply their different professional skills and knowledge to a variety of rural healthcare situations.

Methods and Findings: This article reports on three years of results from the program's evaluation which used a pre-post test mixed method design. The findings show a significant and positive shift in students' attitudes and understanding of interprofessional learning and practice following their participation in RIPPER. The evaluation findings suggest the need for sustainable interprofessional rural health education that is embedded in undergraduate curricula.

Conclusion: The evaluation of RIPPER suggests that exposure of healthcare students to interprofessional education can positively affect their perceptions of collaboration, patient care, and teamwork. The evaluation also points to the rural context as an ideal place to showcase elements of effective interprofessional practice.
\end{abstract}

Keywords: Interprofessional health education; Interprofessional practice; Simulation; Rural health education

Journal of Research in Interprofessional Practice and Education (JRIPE)

Vol. 2.2

(C) 2012

Corresponding author: IJessica. Whelani @@utast.edu.aüi

\section{Introduction}

There is growing national and international evidence that interprofessional education (IPE) has become a key strategy in preparing emerging health professionals for the changing and growing demands and challenges of collaboration and modern healthcare provision [1-10]. IPE is defined in this article as occurring when "two or more professions learn with, from and about each other" [2]. Interprofessional health education is argued to promote enhanced communication, collaboration, and teamwork skills among students to provide more effective healthcare services and improved patient care $[3,5,8,11-13]$. Health professionals, and in particular health educators, from a variety of disciplines are therefore powerfully positioned to develop interprofessional university curricula that emphasize the delivery of health and social care services in a cohesive and collaborative manner.

This article reports on the Rural Interprofessional Program Educational Retreat (RIPPER) pilot initiative, an interprofessional undergraduate health education pro- 
231

Interprofessional Rural Health Education Pilot

Woodroffe, Spencer, Rooney, Le, \& Allen

Journal of Research in Interprofessional Practice and Education

Vol. 2.2

February, 2012 gram at the University of Tasmania, Australia. RIPPER provides students with one of the first opportunities in their undergraduate training to learn from and work with other health science students in an interdisciplinary team, using authentic and relevant situational learning for clinical and professional knowledge and skill building. The RIPPER pilot was implemented over three years from 2006 until 2008. The article provides an overview of the teaching and learning methods employed in the program and reports on the key outcomes from the three years of evaluation. Practical issues associated with the implementation and design of the interprofessional health education pilot are also presented.

\section{Background: Interprofessional rural health education}

Within the wider discipline of health, and particularly rural health, it is now acknowledged that a "collaborative team-oriented approach to care is required to ensure patient safety and quality of service delivery" [10]. This collaborative approach can also be referred to as interprofessional practice, defined in this article as occurring when "all members of the health service delivery team participate in the team's activities and rely on one another to accomplish common goals and improve healthcare delivery, thus improving patient's quality experience" [14].

Given that health practice is critically dependent on effective interprofessional practice to maximize patient safety and outcomes, universities now recognize the need to incorporate interprofessional learning (IPL) into health science curricula [2-9]. There is growing national and international evidence that IPE is emerging as a key strategy in undergraduate health science education for promoting enhanced communication, collaboration, and teamwork skills among students. It commonly involves education initiatives that incorporate interactive learning methods between different professionals to foster collaborative interprofessional practice in the health workplace and in the community [12].

Collaborative practice strengthens healthcare systems by providing more effective healthcare services and improved patient care and outcomes [3,5,8,11-13]. It is argued that IPE may assist in improving how emerging health professionals understand the roles and values of other healthcare disciplines and may increase professional job satisfaction through more effective team-based practices. As Robertson and Bandali argue, the implementation of IPE programs and opportunities in all healthcare areas could assist in significantly reducing the demands on "both the healthcare and education systems" [12] as well as providing "students with the necessary knowledge, skills and attitudes to work effectively together once they enter the actual patient care setting" [12].

Academic and political discourse surrounding the benefits of IPE, particularly in rural areas, have continued to mount as workforce shortages worsen, healthcare delivery costs skyrocket, and the pressures of working with people with chronic diseases and an ageing population has increased [15]. These trends ultimately require new ways of training health professionals to work more effectively. Health professionals, and in particular health educators, from a variety of disciplines are therefore powerfully positioned to develop interprofessional-based curricula that emphasize 
232

Interprofessional Rural Health Education Pilot

Woodroffe, Spencer, Rooney, Le, \& Allen

Journal of Research in Interprofessional Practice and Education

Vol. 2.2

February, 2012 the delivery of health and social care services in a cohesive and collaborative manner. This enables the preparation of future health professionals for collaborative practice to address prevailing health issues within the community. It is argued that effective interprofessional education programs must reflect this changing nature of healthcare provision and collaboration by using interactive and problem-based authentic learning environments [3] that promote group work, reflection, and mentorship [16]. A further component of effective interprofessional health education is the contextual setting in which this occurs [5,6,16-19]. The development and implementation of IPE initiatives in the rural context is of particular interest to this study. Rural-based IPE is argued to be increasingly relevant to strengthening future healthcare teams who work in rural areas because "in rural areas the shortage of health professionals, limited access to specialist services and a broad case-mix increases the need for collaborative professional practice" [15]. Along with exposing emerging health professionals to the necessity of collaborative practice and expertise, rural IPE is seen to be an effective strategy for exposing students to the nature of rural practice, potentially leading to the future recruitment and retention of health professionals to rural areas [19].

There are, however, barriers to the implementation of IPE within both rural and urban contexts. For example, it is argued that few undergraduate curricula within Australia offer health science students the opportunity to learn together to prepare for team-based practice within both the urban and rural contexts [11]. This is particularly problematic for students preparing for rural health practice given that rural practitioners rarely work in isolation. A number of programs have emerged, and are continuing to emerge, in the quest for the development of successful models of rural IPE both internationally and within Australia [6,18-24]. However, it has been noted that within Australia, although there have been some pilot projects with a rural focus, "there are few examples that have translated into ongoing programs, where IPE is valued as core business alongside discipline specific education and training" [23]. This article reports on one such rural IPE initiative in Tasmania.

\section{Methods}

RIPPER is an undergraduate pre-qualification IPE pilot program run by the University Department of Rural Health (UDRH) Tasmania and developed collaboratively by staff from the disciplines of Medicine, Rural Health, Nursing, and Pharmacy. RIPPER's objectives were to develop an innovative undergraduate IPE model that employed interactive and problem-based authentic learning environments to promote and facilitate enhanced communication, collaboration, and teamwork skills among students. The overall goal was to provide a unique opportunity for students to work in a rural setting where the elements of interprofessional practice are seen as integral to the provision of effective healthcare.

\section{Program format}

The RIPPER pilot was based around students learning and interacting with one another through a series of rural healthcare case scenarios. The case scenarios had 
233

Interprofessional Rural Health Education Pilot

Woodroffe, Spencer, Rooney, Le, \& Allen

Journal of Research in Interprofessional Practice and Education

Vol. 2.2

February, 2012 been developed to both promote an interprofessional approach to patient care and also enable students to confront and deal with the challenges of rural healthcare by developing a shared understanding of economic, social, geographical, and political issues. Students worked collaboratively in small clinically relevant interprofessional teams that engaged the expertise and knowledge of each profession. Each team rotated through a series of learning stations/scenarios and was required to attend to and interact with each scenario. Students were expected to develop their knowledge and skills through the immediate management of the case as well as discussion and reflection on issues such as teamwork, development of management guidelines, and strategies for prevention and follow-up care. Time was provided for peer evaluation, guided reflection, and debriefing with health professional and academic facilitators around the management of the scenario.

In developing the case scenarios for RIPPER, experiential and interactive educational high- and low-fidelity simulations were employed to create situations that were as representative as possible of real-life practice. For example, some scenarios used high-fidelity patient training simulators such as SimMan manikins that have advanced physical responses, including talking, blinking, and responding physically to the administration of medication. Other scenarios were focused on low-fidelity simulations such as role play where, for example, professional actors played the part of patients. These actors received coaching and script training from health professionals about how to present the demeanour of a standardized patient [10].

The use of simulation education in the training of pre-qualification health professionals has increased significantly in recent years [25-29]. The advantage of simulation-enhanced educational strategies is that they "replicate authentic clinical encounters" [21] in a "no-risk environment" [10] while also providing the opportunity for students "to learn from error without causing peril to a patient" [27]. Simulation-based education enables students and interprofessional student teams to learn together and to reduce future errors and improve patient safety and care. It is no surprise, therefore, that simulation-based IPE is seen to be a unique opportunity for students to "contextualise their learning by integrating both technical and interpersonal skills" [26]. The use of simulation in RIPPER provided an opportunity for students to engage in experiential learning and to promote and increase communication, teamwork, and leadership skills [11]. It was an opportunity for students to learn and practise in an authentic yet safe and risk-free environment.

RIPPER was also an opportunity for students to have an authentic rural learning experience. The first two iterations (2006-2007) of the program were conducted in a small rural community in Tasmania's North East over two days. Students were immersed in the rural context via a number of processes. For example, all scenarios were rurally focused and relevant, students were supported by local health professionals working in the community who were able offer insight into and knowledge of the nature of rural health. In addition, students were also accommodated locally and catered for by community organizations. Due to a number of issues with student timetabling and facilitator availability, the third iteration (2008) of RIPPER took place at the Northern campus of the University of Tasmania. Students were 
234

Interprofessional Rural Health Education Pilot

Woodroffe, Spencer, Rooney, Le, \& Allen

Journal of Research in Interprofessional Practice and Education

Vol. 2.2

February, 2012 once again exposed to rurally focused case scenarios with facilitators from both rural and regional areas. A more detailed overview of the scenarios and format of RIPPER can be found in previous reports of the RIPPER program [21,30].

\section{Program evaluation}

RIPPER was evaluated over its three-year delivery period (2006-2008). Ethics approval was not required as this program sat under the University's teaching and learning curriculum. A pre-post test mixed method design was developed to gather both qualitative and quantitative data from students before and after the program. A questionnaire was designed using open and closed questions that consisted of qualitative and quantitative components.

Academics and health professionals who assisted in the facilitation of the RIPPER program were also asked to provide comments and reflect on the content, format, and future directions of the pilot. Facilitator evaluation data was collected through informal focus group discussions at the end of the program and informal written feedback by email. This information was collated and analyzed thematically by the project team.

\section{Mixed method approach}

The use of mixed methods in examining the impact of IPE is argued to assist in detecting "changes resulting from an interprofessional course more accurately as there is data collection at two points in time: before and after the course" [31]. In evaluating RIPPER, a pre- and post-survey mixed method evaluative approach was used to evaluate students' understandings and experiences of the program and to assist in detecting any changes to students' attitudes and perspectives resulting from their exposure to the program. Additionally, because the outcomes and effects of IPE are "multidimensional" [10], interprofessional education programs should incorporate a variety of methods [10] "as a way of obtaining reliable and valid evidence" [10].

\section{Data collection}

Quantitative data was collected from students before and after the program using 12 items on the questionnaire. Students were instructed to indicate how strongly they agreed or disagreed with each item on a five-point Likert scale where $1=$ strongly disagree, 2 =disagree, $3=$ neutral, $4=$ agree, and $5=$ strongly agree. The items were statements relevant to various components of the program including students' experiences of teamwork, collaborative and peer learning, interprofessional approaches to patient care, and professional roles and responsibilities. A number of these statements were adapted from the Parsell and Bligh [32] RIPLS scale (readiness for interprofessional learning scale) which is one well-recognized tool for evaluating attitudes to IPE due to its established validity and reliability [30]. However, we did not measure attitudes to IPE; rather, we examined students' attitudes to their experiences of IPE which included analyzing the survey tool to validate its reliability and validity [30]. 
235

Interprofessional Rural Health Education Pilot

Woodroffe, Spencer, Rooney, Le, \& Allen

Journal of Research in Interprofessional Practice and Education

Vol. 2.2

February, 2012

\section{Quantitative data analysis}

Quantitative data were imported into SPSS version 16 (SPSS Inc., Chicago) [33] for analysis. Frequencies and describe functions were run to investigate the data. Paired pre- and post-RIPPER ordinal Likert scale data were investigated using the nonparametric Sign test. This tests whether median pre- and post-RIPPER responses were significantly different and also indicates the direction of the difference (whether the level of agreement with questions increased or decreased). Differences were accepted as significant at $p<0.05$ for all tests.

\section{Qualitative data analysis}

Qualitative data was also collected on eight items using open-ended questions. Students were asked before and after the program to define their perceptions and understanding of interprofessional practice, including the roles and responsibilities of respective health professionals, clinical outcomes (including clinical problem solving and effects on patient care), and the importance of collaboration in a team environment. This qualitative data was coded using a thematic analysis approach [34-35]. Thematic analysis involves the identification of themes or recurring or intersecting patterns in qualitative data. Thematic analysis seeks to establish patterns, consistencies, and meanings that suggest relationships between themes [36]. Coding of the qualitative data was done by organizing and sorting the data into groups and applying codes and labels to these groups to identify intersecting and consistent themes in the data [34-35]. Thematic analysis was also used to code and analyze the information collected from facilitators with each iteration of the RIPPER program. Three of the authors were involved in the thematic coding of the qualitative data (JW, JS, QL). Following independent coding, the team met to discuss the coding and to check for disagreements.

However, there were no disagreements with all involved retrieving similar themes from the data. Some member cross-checking was also conducted during the coding and analysis phase where some facilitators $(n=6)$ from a variety of disciplines were contacted to comment critically on the findings and evaluation of the program. These facilitators had all been consistently involved in the RIPPER program over the three years. This data was then used to clarify key issues from the evaluation and to confirm key directions for developing and implementing RIPPER in the future.

\section{Results}

In total, 90 students participated in the program. Students were from the Schools of Medicine $(n=36)$, Pharmacy $(n=25)$, and Nursing and Midwifery $(n=29)$ at the University's of Tasmania's Faculty of Health Science (these are the three schools in the University of Tasmania's Faculty of Health Science; UTAS does not have allied health or associated undergraduate training courses). Students were typically in the final year of their undergraduate education program and were from University campuses in both Northern and Southern Tasmania. University of Tasmania academics from a variety of disciplines $(n=15)$, and a range of health professionals and specialists $(n=11)$ assisted in facilitating the RIPPER pilot. 


\section{JRIPE}

236

Interprofessional Rural Health Education Pilot

Woodroffe, Spencer, Rooney, Le, \& Allen

Table 1

Student participation in RIPPER by discipline/year

\begin{tabular}{|l|c|c|c|}
\hline & 2006 & 2007 & 2008 \\
\hline Pharmacy & 10 & 6 & 9 \\
\hline Medicine & 12 & 12 & 12 \\
\hline Nursing & 8 & 11 & 10 \\
\hline Total No of Students & 30 & 29 & 31 \\
\hline
\end{tabular}

In regards to the representation of students from each of the three disciplines (see Table 1), the project team attempted to have an even mix of students, but this was difficult due to a number of identifiable reasons including existing student placements, assessment demands, available student numbers, and the non-compulsory nature of RIPPER in the curriculum.

The results of the evaluation from both students' and facilitators' perspectives indicated that the specific numbers of students in the scenarios was not an issue as long as students felt adequately supported by facilitators. In addition, many facilitators believed that "uneven" student numbers in the scenarios reflected the actual nature of clinical practice and that the small team format made it possible for students from all disciplines to interact and learn interprofessionally. Therefore, the uneven mix of students did not appear to have any negative impact on students' experience of RIPPER and this form of IPE.

\section{Table 2}

\section{Distribution of participants' responses questionnaire (on Questions 9, 11, 13, 15, 16, 18, 19)}

\begin{tabular}{|c|c|c|c|c|c|c|c|c|}
\hline & \multirow{3}{*}{ Median } & \multirow{3}{*}{ Mean } & \multicolumn{3}{|c|}{$\begin{array}{l}\text { Pre-RIPPER experience } \\
(N=83, \text { Missing }=7)\end{array}$} & \multicolumn{3}{|c|}{$\begin{array}{l}\text { Post-RIPPER experience } \\
(N=83, \text { Missing }=7)\end{array}$} \\
\hline & & & \multicolumn{2}{|c|}{$95 \%$ Cl for mean } & \multirow{2}{*}{ Median } & \multirow{2}{*}{ Mean } & \multicolumn{2}{|c|}{$95 \% \mathrm{Cl}$ for mean } \\
\hline & & & Upper & Lower & & & Upper & Lower \\
\hline Q9 & 5 & 4.51 & 4.38 & 4.64 & 5 & 4.6 & 4.47 & 4.74 \\
\hline Q11 & 5 & 4.47 & 4.31 & 4.63 & 5 & 4.8 & 4.68 & 4.91 \\
\hline Q13 & 5 & 4.42 & 4.27 & 4.57 & 5 & 4.73 & 4.63 & 4.84 \\
\hline 015 & 4 & 4.3 & 4.12 & 4.48 & 5 & 4.67 & 4.55 & 4.8 \\
\hline 016 & 5 & 4.59 & 4.44 & 4.74 & 5 & 4.84 & 4.73 & 4.96 \\
\hline Q18 & 5 & 4.47 & 4.34 & 4.60 & 5 & 4.81 & 4.71 & 4.91 \\
\hline Q19 & 5 & 4.52 & 4.39 & 4.64 & 5 & 5 & 4.69 & 4.90 \\
\hline
\end{tabular}

Journal of Research in Interprofessional Practice and Education

Vol. 2.2

February, 2012

\section{Quantitative results}

Due to incomplete or missing data, 7 participants were excluded from the analysis; therefore, the results are drawn from the 83 valid cases, of whom 39\% (32) were male and $61 \%$ (51) were female. 
JRIPE

237

Interprofessional Rural Health Education Pilot

Woodroffe, Spencer, Rooney, Le, \& Allen

Table 2 summarizes the mean and median scores for the seven scaled questions (questions 9, 11,13,15,16,18, and 19) used consistently over the three years of data. Table 2 shows a high degree of agreement (higher mean scores) among participants for all seven items.

The results of the Sign test on the seven paired questions before and after RIPPER are shown in Table 3 . Table 3 indicates a significant difference in pre- and postRIPPER scores for all but one item (question 9). Of the 83 participants, 31 responded differently to question 11 on their pre- and post-RIPPER questionnaires, 28 on question 13,35 on question 15,29 on question 16,37 on question 18 , and 36 on question 19 . For each of these, a greater number of people had lower agreement with the question pre-RIPPER compared to post-RIPPER. For example, 26 (92.8\%) of the 28 participants whose level of agreement changed agreed to a greater extent that "learning with other healthcare students helps me become a more effective member of a healthcare team" post-RIPPER compared to pre-RIPPER.

Table 3

\section{Results of Sign test on Q9, 11, 13, 15, 16, 18 and 19 - Comparing the level of agreement between pre-RIPPER and post-RIPPER experience}

\begin{tabular}{|l|c|c|c|c|c|c|}
\hline \multirow{2}{*}{$\begin{array}{l}\text { Test matched pairs } \\
\text { (N=83) }\end{array}$} & \multicolumn{2}{|l|}{ Negative Differences } & \multicolumn{2}{l|}{ Positive Differences } & z-value & $\begin{array}{c}p \text {-value } \\
\text { (2-tailed) }\end{array}$ \\
\cline { 2 - 8 } & $N$ & $\%$ & $N$ & $\%$ & & \\
\hline $\begin{array}{l}\text { Q9 Pre-Post RIPPER } \\
\text { Understanding resources and networks } \\
\text { required in the rural community }\end{array}$ & 22 & 64.7 & 12 & 35.3 & -1.543 & 0.123 \\
\hline $\begin{array}{l}\text { Q11 Pre-Post RIPPER } \\
\text { Benefits to patients of working together }\end{array}$ & 26 & 83.9 & 5 & 16.1 & -3.592 & $<0.0001$ \\
\hline $\begin{array}{l}\text { Q13 Pre- Post RIPPER } \\
\text { Becoming a more effective member of a } \\
\text { healthcare team }\end{array}$ & 26 & 92.8 & 2 & 7.2 & -4.347 & $<0.0001$ \\
\hline $\begin{array}{l}\text { Q15 Pre- Post RIPPER } \\
\text { Increased understanding of clinical problems }\end{array}$ & 30 & 85.7 & 5 & 14.3 & -4.057 & $<0.0001$ \\
\hline $\begin{array}{l}\text { Q16 Pre Post RIPPER } \\
\text { Team working skills are essential for all } \\
\text { healthcare students to learn }\end{array}$ & 23 & 79.3 & 6 & 20.7 & -2.971 & 0.003 \\
\hline $\begin{array}{l}\text { Q18 Pre-Post RIPPER } \\
\text { Improved working relationships after training }\end{array}$ & 32 & 86.5 & 5 & 13.5 & -4.274 & $<0.0001$ \\
\hline $\begin{array}{l}\text { Q19 Pre-Post RIPPER } \\
\text { Better understanding of other professions' } \\
\text { roles and responsibilities }\end{array}$ & 29 & 80.6 & 7 & 19.4 & -3.500 & 0.000 \\
\hline
\end{tabular}

Notes: a) Where level of agreement of Pre-RIPPER < level of agreement of Post-RIPPER; b) Where level of agreement of Pre-RIPPER > level of agreement of Post-RIPPER

Journal of Research in Interprofessional Practice and Education

Vol. 2.2

February, 2012 
Interprofessional Rural Health Education Pilot

Woodroffe, Spencer, Rooney, Le, \& Allen

Journal of Research in Interprofessional Practice and Education

Vol. 2.2

February, 2012

\section{Journal of Research in Interprofessional Practice and Education}

In summarizing the results of the quantitative data, the questions aimed to measure students' attitudes to shared learning and teamwork, their perceptions of other healthcare professionals, and their understandings of the benefits of collaboration and teamwork. In the pre-evaluation quantitative questionnaire most students demonstrated a positive attitude toward team learning and the benefits of collaboration and teamwork with the majority of responses being "agree." However, in the post-program questionnaire a large number of these responses increased to "strongly agree." The post-program results demonstrated a predominantly positive shift in students' understanding of interprofessional practice and its benefits and the importance of understanding the roles and skills of other healthcare professionals. All post-program quantitative questions revealed a positive shift in students' responses. The most significant statistical shifts existed under the themes of the importance of peer learning and multidisciplinary undergraduate education, the importance of learning teamworking skills, the importance of learning with other healthcare professionals to increase teamwork and cooperation, and the benefit of interprofessional practice for patient outcomes.

\section{Qualitative results}

The results of the qualitative data can be summarized into five key areas related to the students' understandings of IPE following their participation in the RIPPER pilot. Across the three years of evaluation data, similar themes and issues emerged: the importance of learning together, the importance of working together for the benefits to patients, understanding of other health professionals' roles and responsibilities, the importance of developing teamworking skills, and understanding of rural health issues. An overview of these themes will be presented in the following section. Additional qualitative data collected from facilitators of the RIPPER program over the three years will also be presented.

\section{"Learning Side by Side": The importance of interprofessional learning}

One of the key findings from the three years of evaluation was the shift in the value that students ascribed to learning together with other health professional students post-RIPPER. When students were asked to identify the most positive aspects of the program, more than $90 \%(n=75)$ specifically identified learning alongside other students as the most valued and useful part of their experience in RIPPER. The following comments exemplify how students stressed the importance of the opportunity to learn interprofessionally:

I enjoyed the opportunity to learn and work with Nursing and Pharmacy students; we have never really done this in our six years of uni before. (Medical Student)

Invaluable, we need more interdisciplinary training throughout our degree. (Nursing Student)

In specifically examining what students believed to be the most useful and effective aspects of their participation in RIPPER, three key areas were identified. These 
Interprofessional Rural Health Education Pilot

Woodroffe, Spencer, Rooney, Le, \& Allen

Journal of Research in Interprofessional Practice and Education

Vol. 2.2

February, 2012

\section{Journal of Research in Interprofessional Practice and Education}

included the fact that students recognized that learning together assisted them in three areas: (i) in becoming a more effective member of a team, (ii) in increasing their ability to understand clinical problems, and (iii) in improving working relationships after completing undergraduate training.

\section{Becoming a more effective member of a healthcare team}

In response to the question "learning with other healthcare students helped them become more effective members of a healthcare team" (question 13), there was a positive shift from the pre-test responses to the post-test responses of students. For example, in the pre-test, $50 \%(n=41)$ strongly agreed and $40.9 \%(n=34)$ agreed with the statement, whereas in the post-test $75.9 \%(n=63)$ strongly agreed and $21.8 \%$ $(n=18)$ agreed. The Sign test confirmed a significant differential level of agreement for pre- and post-RIPPER $(z=-4.347, p<0.0001)$, with more students strongly agreeing with this statement following their IPE experience than in the pre-test evaluation. The following comments were made about how working with other students had influenced their ability and effectiveness of a healthcare team member:

It [RIPPER] reinforced that teams are more effective in providing care due to varying experiences ... I am part of a team, not just a nurse. (Nursing Student)

I've definitely got more of an understanding of the importance of an interdisciplinary team approach and how it benefits all involved. (Medical Student)

\section{Understanding of clinical problems}

The process of learning with other students was perceived as assisting students to better understand clinical problems (question 15$)$. In the pre-test, $46.6 \%(n=39)$ of students strongly agreed and $30.7 \%(n=25)$ agreed with the statement "learning with other healthcare students helps increase their abilities to understand clinical problems," whereas in the post-test, $86.2 \%(n=71)$ of students strongly agreed and $11.5 \%(n=9)$ agreed. The Sign test confirmed a significant differential in the level of agreement for pre- and post-RIPPER $(z=-4.057, p<0.0001)$. The following comments were made by students to show the ways in which they perceived that learning alongside other students helped them to understand and work through clinical issues and problems:

It has taught me how team work and communication are important, clinically and diagnostically to manage a problem and how to handle myself in critical situations. (Medical Student)

It gave me hands on experience, having people giving their input in real life situations. (Nursing Student)

It has introduced me to the challenges others face in hospitals which will help me better communicate in the future. (Medical Student) 
Interprofessional Rural Health Education Pilot

Woodroffe, Spencer, Rooney, Le, \& Allen

Journal of Research in Interprofessional Practice and Education

Vol. 2.2

February, 2012
Journal of Research in Interprofessional Practice and Education

Students also recognized that interprofessional learning has the capacity to positively improve the way in which they will practise interprofessionally in their future careers.

\section{Peer learning among healthcare students can improve working relationships after training/qualification}

In response to the statement "peer learning amongst health science students could improve working relationships after training" (question 18), the pre- and post-survey showed a positive shift in the number of students who strongly agreed with this statement following their involvement in RIPPER. For example, in the pre-test, $44.3 \%(n=37)$ of students agreed and $51.1 \%(n=42)$ strongly agreed with the statement, while in the post-test, $13.8 \%(n=11)$ of students agreed and $83.9 \%(n=70)$ strongly agreed. This demonstrates a considerable increase in the number of students who strongly agreed with the statement that peer learning among healthcare students can improve working relationships after training/qualification following their involvement in RIPPER. The Sign test confirmed a significant differential level of agreement for pre- and post-RIPPER, with $86.5 \%$ of those who responded differently to the item pre- and post-RIPPER indicating a greater level of agreement in the post-test $(z=-4.274, p<0.0001)$. In supporting this shift, the following comments show how the RIPPER program influenced students' perceptions of each other and also their ability to work together positively in the future.

I've really enjoyed working with medical and pharmacy students, and it makes them seem more approachable when I leave here (University). (Nursing Student)

I will feel much more comfortable working alongside doctors and nurses in the future. (Pharmacy Student)

\section{Benefits to Patients of Working Together}

A second key theme to emerge from the evaluation data was a shift in how greater benefits to patients could be gained through interprofessional learning and practice. In the pre-test, $28.4 \%(n=24)$ of students agreed and $60.2 \%(n=50)$ strongly agreed with the statement that "patients will ultimately benefit if healthcare students work together to solve patient problems" (question 11), while in the post-test $13.8 \%$ of students agreed and $82.8 \%(n=69)$ strongly agreed. The Sign test indicated a significant differential level of agreement for pre- and post-RIPPER questionnaires $(z=-3.592$, $p<0.0001)$. The positive shift in response to this item is supported by a number of statements to the open-ended qualitative question regarding how, and if, students thought the process of working together may improve patient and clinical outcomes:

Every role is important and each profession contributes different strengths, and if we use these skills effectively and cumulatively, patient outcomes as well as self satisfaction is [sic] greatly enhanced. (Medical Student) 
Interprofessional Rural Health Education Pilot

Woodroffe, Spencer, Rooney, Le, \& Allen

Journal of Research in Interprofessional Practice and Education

Vol. 2.2

February, 2012
Journal of Research in Interprofessional Practice and Education

Better appreciation of how a team can effectively work together for a patient even if they aren't familiar with each other. (Nursing Student)

At the end of the day we all have a common goal ... the patient. (Medical Student)

Students' recognition of the benefits to patients through working collaboratively was also clearly evident in their responses to the open-ended question concerning their perceptions of key features of interprofessional practice. Students' comments included

Working together as a team for optimal management of the patient. (Pharmacy Student)

Professionals working together, pooling expertise to bring about solutions for the benefit of the patient. (Nursing Student)

Working with other disciplines using your own and their strengths to the benefit of the patient. (Medical Student)

\section{Understanding of professional roles and responsibilities}

The third theme to emerge from the data was a greater understanding among students of the roles and responsibilities of other healthcare students. In the postRIPPER questionnaire students showed stronger agreement that "learning with other health professionals gives me a better understanding of their roles and responsibilities" (question 19). In the pre-survey, 39.8\% $(n=33)$ agreed and 55.7\% $(n=46)$ strongly agreed and in the post-survey, $14.9 \%$ of students $(n=12)$ agreed and $81.6 \%$ $(n=68)$ students strongly agreed. The Sign test confirms a significant differential level of agreement for pre- and post-RIPPER $(z=-3.500, p<0.0001)$. When students were further asked how the RIPPER program had influenced, if at all, their understanding of themselves as emerging health professionals their responses included the following:

I now know more about what the other health professionals do ... helpful for next year when I am out there doing this stuff in practice. (Pharmacy Student)

It gave me insight into how my interventions are used as a diagnostic tool by the doctor, but it also clarified my role as a nurse and gave me more confidence in my abilities. (Nursing Student)

It [RIPPER] helped me understand my role in the interprofessional healthcare team, my limitations and strengths and areas I need to improve on, e.g., leadership. (Medical Student)

\section{Teamworking skills}

A fourth theme from the evaluation concerned teamworking skills. The majority of students indicated agreement that teamworking skills are essential for all healthcare students to learn (question 16). In the pre-survey, 30.7\% $(n=25)$ of students agreed 


\section{JRIPE}

242

Interprofessional Rural Health Education Pilot

Woodroffe, Spencer, Rooney, Le, \& Allen
Journal of Research in Interprofessional Practice and Education

Vol. 2.2

February, 2012

\section{Journal of Research in Interprofessional Practice and Education}

and $64.8 \%(n=54)$ strongly agreed and in the post-survey, $11.5 \%$ of students agreed $(n=9)$ and $86.2 \%(n=71)$ strongly agreed with the statement regarding teamworking skills. The Sign test indicated a significant differential level of agreement for preand post-RIPPER $(z=-2.971, p=<0.003)$, but this shift was not as significant as earlier themes. The following comments by students in the qualitative evaluation questions demonstrated the ways in which students' attitudes to teamwork had changed as a result of their participation in the RIPPER program.

It also taught me that it was okay to not know everything and to ask what others thought. (Medical Student)

I have walked away realising that there is no point trying to work alone when you have other professions there to work with. (Medical Student)

It reinforced that teams are more effective in providing care due to varying experiences ... I am part of a team not just a nurse. (Nursing Student)

\section{Understanding of rural health issues}

Fifty-four $(64.7 \%)$ of the students indicated agreement that the program had provided them with a greater understanding of the resources and networks required to assist people with health related problems in the rural community (question 9). However, there was no significant difference in the level of agreement to question 9 in the pre- and post-RIPPER questionnaires. The following comments are indicative of this understanding:

RIPPER provided ways of managing patients individually in rural areas, and other things that can be done with the limited resources and facilities in rural areas. (Pharmacy Student)

Fantastic weekend, very important to work as a team and see how that works in rural health. (Medical Student)

(RIPPER gave me a) greater understanding of the challenges and ways to overcome these in rural medicine. (Medical Student)

\section{Additional student learning}

Additional data was also collected on what students perceived to be the most useful parts of the RIPPER program. Students made the following comments about the benefits of the RIPPER program in respect to interprofessional learning and the use of IPE-based simulation in preparing them for future practice and collaboration:

Working under pressure in situations we may encounter in clinical practice. (Medical Student)

Hands on experience, having people (pharmacist, GP's, etc.) giving their input in real life situations. (Nursing Student) 
243

Interprofessional Rural Health Education Pilot

Woodroffe, Spencer, Rooney, Le, \& Allen

Journal of Research in Interprofessional Practice and Education

Vol. 2.2

February, 2012
Getting a first-hand experience on handling acute settings and the mix of a variety of real life common situations. (Pharmacy Student)

The qualitative data showed that students who participated in RIPPER recognized that learning and working in a non-threatening simulated environment enabled them to "learn from their mistakes" and reflect on their own roles, responsibilities, and skills. Many recognized as beneficial to their own learning "the reallife nature" of the scenarios employed in the program. They also acknowledged that the authenticity of the scenarios assisted in not only highlighting the essential nature of teamwork and collaboration, but also prepared them for "real patients" and their "not-too-distant future career." Other observations from students about the value of the RIPPER experience included increased confidence, increased understanding of each other's roles, the importance of the contributions of each health professional's role in the team, the importance of helping each other, recognition of the different strengths each profession could contribute, the importance of working in a team for best patient outcomes, the importance of effective communication, and the importance of sharing ideas and opinions.

\section{Facilitator evaluation and reflection}

In addition to the evaluation of students' responses to the pre- and post-program questionnaires, academics and health professionals who assisted in the facilitation of the RIPPER program were also asked to provide comments and reflections on the running, content, and future directions of the pilot in the form of informal written feedback and group interviews at the completion of the program. In total, written feedback was received from more than half of the facilitators $(n=15)$, with all facilitators being involved in group discussions following each iteration of the program $(n=26)$. From this consultation process, the team responsible for the design and implementation of the RIPPER pilot was able to use this information to refine each iteration of the program. Facilitators identified several issues as impacting on the RIPPER pilot:

\section{Timetabling and integration in health science curriculum}

An ongoing issue for the RIPPER pilot was the need for the program or a similar program to be embedded within the health science curriculum at the University of Tasmania. Issues such as semester timelines were different for each of the three disciplines involved in the program (Nursing, Medicine, and Pharmacy), making it difficult to recruit students and set dates for the pilot. Similarly, given that for many students few if any opportunities existed for interprofessional learning and practice in their undergraduate degree, facilitators and academics all agreed that interprofessional education opportunities needed to be part of undergraduate health science education in all years.

Increased opportunities for rural based health education

Across the three years of the RIPPER pilot, facilitators supported the view that stu- 
244

Interprofessional Rural Health Education Pilot

Woodroffe, Spencer, Rooney, Le, \& Allen

Journal of Research in Interprofessional Practice and Education

Vol. 2.2

February, 2012 dents should have more time practising interprofessionally in rural areas. While RIPPER provided some insight into the issues associated with providing care and working interprofessionally within a rural context, the evaluation showed that longer and more sustained opportunities for students to experience working in rural areas were needed throughout their undergraduate training. This once again supports the need for rural-based interprofessional education to be embedded within the curriculum.

\section{Resources and funding}

One of most positive findings from the evaluation of RIPPER was the interprofessional blend of facilitators and academics involved in the pilot and the mentorship of students. The opportunity for students to not only learn and practise together but also to be guided and taught by an interprofessional team of health practitioners and academics was seen by both facilitators and students as one of the most positive aspects of the RIPPER program. However, the commitment of these facilitators-and particularly the health professionals and specialists who volunteered their time to facilitate-to the pilot program was often outside of and above the scope of their normal working commitments. Additionally, the costs associated with running RIPPER were also significant in that each year more than 50 students and facilitators were accommodated, catered for, and transported.

\section{Discussion}

The findings from the evaluation of RIPPER over three years suggest that the program has been successful in promoting the value of and need for undergraduate health science students learning with and from one another in a relevant and supportive environment. It is important to note that the evaluation findings acknowledged that the students themselves identified the value and importance of interprofessional learning and collaborative practice. The most significant statistical shifts existed under the themes of the importance of peer learning and multidisciplinary undergraduate education, the importance of learning teamworking skills and learning with other healthcare professionals to increase teamwork and cooperation, and the benefit of interprofessional practice for patient outcomes. The fact that students ascribed such important value to the experience of learning together with other healthcare students may also be attributable to the fact that this was their first interprofessional learning experience in their undergraduate training, compounded by their opportunity to observe role models: the academic and clinical mentors/facilitators running RIPPER themselves worked collaboratively together. In addition, students identified the importance of working and learning collaboratively and effectively to maximize patient outcomes and improve working relationships after training. This supports a growing body of discourse surrounding the benefits of IPE [2-5,9-11,8-12,19,23]. As Stone [37] argues, "evidence that IPL improves health outcomes and patient safety is slowly building and has already shown to be effective in reducing clinical error, improving collaborative team behaviour and supporting team culture." 
245

Interprofessional Rural Health Education Pilot

Woodroffe, Spencer, Rooney, Le, \& Allen

Journal of Research in Interprofessional Practice and Education

Vol. 2.2

February, 2012
This study also suggests that RIPPER is an effective model for interprofessional learning and practice in the rural context. The evaluation highlighted that student exposure to rural health issues seemed to result in an increased awareness of the nature of rural healthcare provision and the importance of professional collaboration and building of rural healthcare teams. However, an ongoing limitation of the program is the need for students' exposure to rural areas to be longer and more sustained if students are to gain a more comprehensive insight into the nature of interprofessional and rural practice. In light of an under-resourced rural workforce, the embedding of positive learning experiences relevant to rural practice could enhance the future recruitment and retention of staff.

One of the most critical findings was the strong need for IPE opportunities and programs such as RIPPER to be established as integral parts of formal teaching and assessment within universities rather than as optional or extracurricular activities [37]. The organization and engagement of students from three different disciplines to participate in RIPPER was an ongoing difficulty and highlights the need for IPE to be validated by embedding it in the curriculum of health science students at the University of Tasmania and elsewhere [21]. Additionally, in moving to a model of education that embraces IPE, this study supports the view that "a major investment in capital and curriculum development and most importantly the establishment of strong partnerships and collaborations amongst academic and healthcare institutions" [12] is required for successful IPE initiatives.

The study utilized a pre- and post-intervention assessment of students' perceptions of an interprofessional learning experience in a single group. One limitation of the design of this study is that data was analyzed from a pre-experimental design with no control group and therefore we cannot determine the extent to which the observed changes were a result of the intervention itself or other external factors such as environmental or workplace influences, or participants' previous learning experiences. Selection bias may also have occurred, with students and professionals who had an existing interest in rural issues and interprofessional working being more likely to participate in the RIPPER program.

\section{Conclusion}

The evaluation data suggests that students' participation in RIPPER $(n=90)$ over three separate years has resulted in a positive shift in how students view interprofessional practice and education. Students identified the importance of teamwork for collaboration in practice, clinical problem solving, and positive patient outcomes. The program also generated a greater understanding among students of the networks and resources necessary for rural healthcare practice. The evaluation of the RIPPER program suggested that students perceived it to be a highly beneficial experience, with many students and staff expressing their desire to participate in more interprofessional learning opportunities throughout the undergraduate curriculum. Participation in the program was the first opportunity for most students to learn interprofessionally in their undergraduate curriculum, reinforcing that health professionals "for the most part are educated in silos" [11] and further supporting the 
JRIPE

246

Interprofessional Rural Health Education Pilot

Woodroffe, Spencer, Rooney, Le, \& Allen

Journal of Research in Interprofessional Practice and Education

Vol. 2.2

February, 2012 need for educational strategies such as rural IPE in order to improve a collaborative team-oriented approach to rural healthcare practice.

The authors believe that to be truly effective, IPE requires a number of interprofessional learning activities to be incorporated as core and vertically integrated components of the University of Tasmania's health science curriculum. This article has offered insight into the key issues affecting the design and implementation of a rural IPE program. Further research is required into how IPE can be integrated into undergraduate health science curricula. Health educators from a variety of disciplines are most powerfully positioned to develop these interprofessional-based curricula that emphasize the delivery of health and social care services in a cohesive and collaborative manner.

\section{Acknowledgements}

The authors would like to acknowledge the team of health professionals and University of Tasmania academics for their commitment to and involvement in the various aspects of the design, development, and implementation of the RIPPER program in rural Tasmania.

\section{References}

1. National Rural Health Alliance (NHRA):-(1996):-Austratiān-Héalth Mintstêrs'Cōnference-Kationat,

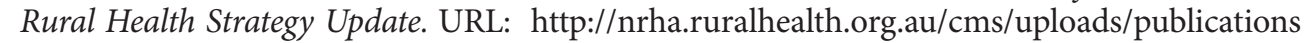
I/Lh_1996_07.pdf.'][February 12, 2009].

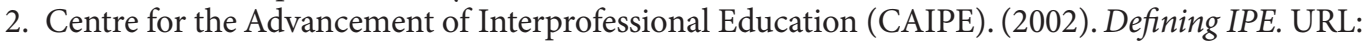
hthttp://wwww.caipe.org.uk:

3. Humphris, D. \& Hean, S. (2004). Educating the future workforce: Building the evidence about interprofessional learning. Journal of Health Services Research and Policy, 9(1), 24-27.

4. World Health Organization. (1988). Learning together to work together for health. Report of a WHO Study Group on multiprofessional education of health personnel: The team approach. Technical report no. 769. Geneva: World Health Organization.

5. Barr, H. (2005). Effective interprofessional education: arguments, assumptions and evidence. Oxford: Blackwell.

6. Stone, N. \& Smith, T. (2007). The RIPENing: Advancing rural interprofessional education in Australia. Paper presented at National Rural Health Conference, Albury, March 7-10, 2007.

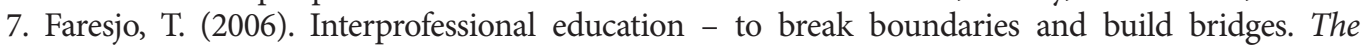
internationat Etectronte fournat of Ruraliand Remote Health, 6, 602. URL:'http://www.rrh.org.aul 1/publishedarticles/article_print_602.pdf'] [November 15, 2011].

8. Gilbert, J.H.V. \& Yan, J. (2009). Framework for Action on Interprofessional Education and Collaborative Practice. World Health Organization.

9. Geller, Z., Rhyne, R., Hansbarger, L., Borrego, M., Van Leit B., \& Scaletti, J., (2002). Interdisciplinary health professional education in rural New Mexico: A 10 year experience. Learning in Health and Social Care, 1, 22-46.

10. Nisbet, G., Hendry, G., Rolls, G., \& Field, M. (2008). Interprofessional learning for pre-qualification health care students: An outcomes-based evaluation. Journal of Interprofessional Care, 22(1), 57-68.

11. Robins, L., Brock, D., Gallagher, T., Kartin, D., Lindhorst, T., Odegard. P.S., Morton, T.H., Belza, B., (2008). Piloting team simulations to assess interprofessional skills. Journal of Interprofessional Care, 22(3), 325-328.

12. Robertson, J. \& Bandali, K. (2008). Bridging the gap: Enhancing interprofessional education using simulation. Journal of Interprofessional Care, 22(5), 499.

13. Hale, C. (2003). Interprofessional education: The way to a successful workforce? British Journal of Therapy and Rehabilitation, 10, 122-127. 
247

Interprofessional Rural Health

Education Pilot

\section{Woodroffe,} Spencer, Rooney, Le, \& Allen

Journal of Research in Interprofessional Practice and Education

Vol. 2.2

February, 2012
14. AIPPEN Australasian Interprofessional Practice and Education Network. (2010). Working

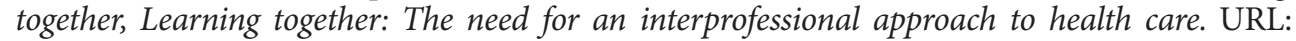
ihttp://www.aippen.net/what-is-ipe-ipl-ipp\#ipp_[October 22, 2009].

15. Smith, T. (2005). The challenge of evaluating rural undergraduate multi-professional education. Paper presented at National Rural Health Conference, Alice Springs March 2005, 10-13.

16. McNair, R., Brown, R., Stone, N., \& Sims, J. (2001). Rural interprofessional education: Promoting teamwork in primary health care education and practice. Australian Journal of Rural Health 2001, 9 (supplement), S19-S26.

17. Pirrie, A., Hamilton, S., \& Wilson, V. (1999). Multidisciplinary education: Some issues and concerns. Educational Research 1999, 41(3), 301-314.

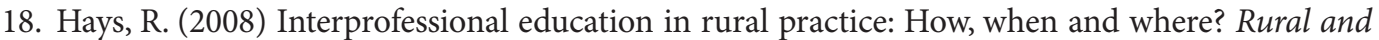
Remote Health, 8, 939. URL:'http://www.rrh.org.au']'[November 15, 2011].

19. Medves, J., Paterson M., Chapman, C., Young, J., Tata, J., Bowes, D., Hobbs, N., McAndrews, B., \&

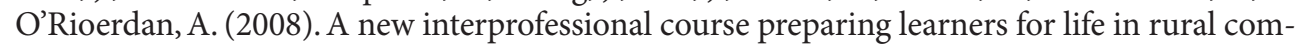
'munities. Rurat and Remote Health, 8, 836. URL: 'http://www.rrh.org.au/publishedarticles! '/article_print_8 3 36.

20. Dalton, L., Spencer, J., Dunn, M., Albert, E., Walker, J., \& Farrell, G. (2003). Re-thinking approaches to undergraduate health professional education: Interdisciplinary Rural Placement Program. Collegian, 10(1), 17-21.

21. Whelan, J., Spencer, J., \& Rooney, K. (2008). A RIPPER project: Advancing interprofessional rural

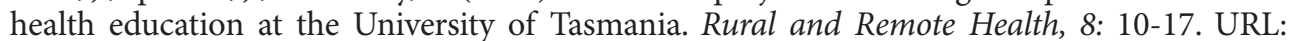
'http://www.rrh.org.au/publishedarticles/article_print_1017.pdf'][September 24, 2009].

22. Charles G., Bainbridge L., Copeman-Stewart K., Art S.T., Kassam R. (2006). The Interprofessional Rural Program of British Columbia (IRPbc). Journal of Interprofessional Care, 20(1), 40-50.

23. Lewis, B. \& Stone, N. (2007). Shaping a sustainable interprofessional education program. Focus on Health Professional Education: A multidisciplinary journal, 8(3): 28.

24. Liaw, S., McGrath, B., Jones, G., Russell, U., Bourke, L., \& Hsu-Hage, B. (2005). A compulsory expe-

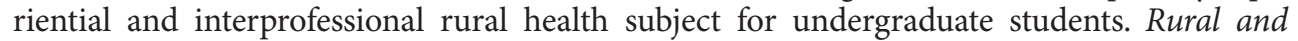
Remote Health, 5, 460. URL: 'Lhttp://www.rrh.org.au/publishedarticles/article_print_460.pdf.' [September 24, 2009].

25. Salas, E., Wilson, K., Burke, S., \& Priest, H. (2005). Using simulation based training to improve patient safety, what does it take? Journal on Quality and Patient Safety, 31(7), 363- 371.

26. Bandali, K., Parker, K., Mummery, M., \& Preece, M. (2008). Skills integration in a simulated and interprofessional environment: An innovative undergraduate applied health curriculum. Journal of Interprofessional Care, 22(2), 179-189.

27. Reilly, A. \& Spratt, C. (2007). The perceptions of undergraduate student nurses of high fidelity simulation-based learning: A case report from the University of Tasmania. Nurse Education Today, 27, 542-550.

28. Banks, E., Chudnoff, S., Karmin, I., Wang, C., \& Pardanani, S. (2007). Does a surgical simulator improve resident operative performance of laparoscopic tubal ligation? American Journal of Obstetrics and Gynaecology, 197(5), 541-542.

29. Gore, T., Hunt, C., \& Raines, K. (2008). Mock hospital unit simulation: A teaching strategy to promote safe patient care. Clinical Simulation in Nursing, 4(3), e57-e64.

30. Le, Q., Spencer, J., \& Whelan, J. (2008). Development of a tool to evaluate health science students' experiences of an interprofessional education program. Annals Academy of Medicine-Medical Education, (12), 1027-1033.

31. Freeth, D., Reeves, S., Koppel, I., Hammick, M., \& Barr, H. (2005). Evaluating interprofessional educa-

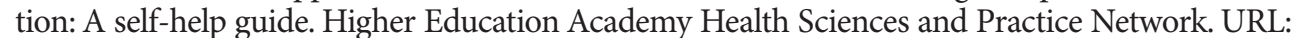
htttp://www.health.heacademy.ac.uk/doc/mp/04-16 hughbarr.pdf/viewi'[October 10, 2009].

32. Parsell, G., \& Bligh, J. (1999). The development of a questionnaire to assess the readiness of health care students for interprofessional learning (RIPLS). Medical Education, 1999(22): 95-100.

33. Green, S.B, Salkind, N., \& Akey, T. (2000). Using SPSS for Windows - Analysing and understanding data (2nd edition). New Jersey: Prentice Hall.

34. Hansen, E. (2006). Successful qualitative health research: A practical introduction. Crow's Nest, New South Wales: Allen and Unwin.

35. Liamputtong, P., \& Ezzy, D. (2005). Qualitative research methods. South Melbourne: Oxford University Press.

36. Gray, D. (2004). Doing research in the real world. London, UK: Sage Publications.

37. Stone, J. (2010). Moving interprofessional learning forward through formal assessment. Medical Education, (44), 396-403. 